\title{
NOSSOS CLÁSSICOS
}

\author{
Paul Vidal de La Blache \\ $(1845-1918)$
}

\section{Uma epistemologia em construção: diálogos entre a Geografia e a Sociologia em Paul Vidal de la Blache}

Continuando nosso esforço de apresentar em língua portuguesa alguns dos textos que se tornaram referência na constituição da ciência geográfica, eis Les conditions géographiques des faits sociaux, palestra feita por Paul Vidal de la Blache na École des Hautes Études sociales e publicada nos Annales de Géographie no ano de 1902.

A primeira coisa a dizer sobre este texto é que ele faz parte de um plano mais geral das jovens Ciências do Homem em busca da conformação e delimitação de seus objetos. Sob esse prisma inserem-se Les règles de la méthode sociologique (1895), de Durkheim, e Introduction aux études historiques (1898), de Charles-Victor Langlois e Charles Seignobos. Não é por acaso que os três fazem parte da mesma geração e que compartilham reflexões que visam à definição de um método e à especificidade de suas respectivas ciências. Naquela ocasião, era preciso separar-se das narrativas exóticas e descritivas dos viajantes, das perspectivas literária e generalista da História e do universalismo metafísico na interpretação da vida social. Tal finalidade seria alcançada através de elementos considerados singulares a cada ciência e de procedimentos operacionais que forjassem um método igualmente particular. Com isso, as Ciências Humanas combatiam o ponto de vista totalizante e global que caracterizara os pensamentos de Kant, Hegel, Comte e Marx. Fragmentava-se o mundo em "objetos" sublinhando antes suas especificidades que semelhanças. Interrogar-se sobre como apreender os fenômenos era, antes de tudo, identificar aquilo que poderia ser (ingenuamente) apropriado e batizado como "monopólio" por cada ciência. E é no interior desta problemática que entra, de forma redentora, o papel do método. Cada uma delas pretendia ser hegemônica frente às demais e, em suas querelas, utilizavam 
argumentos como a "não-cientificidade" deste ou daquele artifício, a ambição demasiada de querer explicar todos os aspectos da vida social, resquícios mitológicos e folclóricos etc.

No intuito de delimitar um campo de atuação, Vidal sustenta que a Geografia não é uma ciência "puramente humana", como o são a Sociologia e a História: ela parte da terra para o homem, e não o inverso (VIDAL DE LA BLACHE, 1903:240; 1904:313). É uma "ciência dos lugares, e não dos homens" (VIDAL DE LA BLACHE, 1913:229). Entretanto, mesmo se inspirando nas Ciências Naturais para agrupar, classificar e subdividir os fenômenos (VIDAL DE LA BLACHE, 1902:23), era necessário esclarecer as diferenças entre ambas: "Ao refletir, fiquei impressionado com os mal-entendidos que reinam sobre a própria idéia da Geografia. No grupo das Ciências Naturais, ao qual sem nenhuma dúvida se integra, ela possui um lugar à parte. Suas afinidades não excluem sensíveis diferenças. Ora, é sobretudo a respeito dessas diferenças que as idéias são pouco precisas" (VIDAL DE LA BLACHE, 1913: 289). Enfatize-se: Vidal sabia que o que estava fazendo não era História, Ecologia ou Sociologia. Ele estava consciente do caráter sui generis da disciplina que ajudava a edificar.

Mas erigir uma epistemologia propriamente geográfica não significava, necessariamente, que o caminho de diálogo possibilitado pelo aporte das outras ciências estivesse interditado. Nesse sentido, Vidal (e, na mesma época, Ratzel) parece avançar em relação aos sociólogos e historiadores de seu tempo: embora correndo o risco de ser acusado de empréstimos indevidos (denotando, assim, ausência de um domínio específico), insistia no fato de que a interdisciplinaridade era um item capital no desenvolvimento do campo científico' ${ }^{\prime}$. A geografia não se encerrava em si mesma: seja por causa do alcance do objeto, que abarcava a relação homem-meio por toda a superfície terrestre e exigia o manejo de uma série de conhecimentos, seja por conta do estatuto "híbrido", ora inclinada a uma

' É o que ele faz questão de esclarecer em Des caractères distintifs de la Géographie, demonstrando em plena I Guerra Mundial uma visão de vanguarda no que tange aos intercâmbios científicos: "A Geografia é considerada como se alimentando nas mesmas fontes de fatos da Geologia, da Física, das Ciências Naturais e, de certa forma, das Ciências Sociológicas. Ela serve-se de noções, sendo que algumas delas são o objeto de estudos aprofundados nas ciências vizinhas. Daí vem então a crítica que se faz, às vezes, à Geografia: viver de empréstimos, intervir indiscretamente no domínio das outras ciências, como se houvesse compartimentos reservados nesse domínio. Na realidade, como veremos, a Geografia possui seu próprio campo. O essencial é considerar qual uso ela faz dos dados sobre os quais se exerce. Será que aplica métodos que lhe pertencem? Que traz novos horizontes de onde as coisas possam aparecer em perspectiva especial? Que os mostra sob um ângulo novo? $\mathrm{O}$ problema todo está aí. Na complexidade dos fenômenos que se entrecruzam na natureza, não se deve ter uma única maneira de abordar o estudo dos fatos; é útil que eles sejam observados sob ângulos diferentes. E se a Geografia retoma certos dados que possuem outro rótulo, não há nada que se possa taxar essa apropriação de anticientífica". (VIDAL DE LA BLACHE, 1913:289-290, grifo nosso; na edição brasileira, 1982:37-38). 
abordagem mais naturalista, ora ressaltando a dinâmica propriamente humana; nesse jogo de equilíbrio instável Vidal esboçava uma Geografia do contato e da aproximação com as Ciências Humanas e Naturais.

Esse é o ambiente no qual se insere o artigo em tela, que versa sobre a contribuição da Geografia ao estudo da sociedade e aos vínculos e dessemelhanças entre ela e a Sociologia. Seu núcleo consiste em ressaltar que os fatos sociais estão sujeitos a determinadas condições geográficas das quais não é possível manterse à margem, pois parte da formação das sociedades é derivada das respostas ao meio que elas mesmas engendraram historicamente. Numa abordagem que pode ser entendida como uma resposta a Durkheim e seus seguidores que, no final do século XIX, lançaram uma série de críticas à Geografia no L'Année Sociologique (RHEIN, 1982), Vidal procura subsídios onde seja possível assegurar que a constituição de traços sociais específicos encontrados em sociedades diferentes deve-se aos elementos geográficos. Raciocinando assim, uma das causas da distinção entre sociedades reside na posição. A floresta tropical africana, por exemplo, dificultava imensamente a troca e o vínculo entre seus habitantes (embora o contato não fosse nulo, como aponta a amizade ou inimizade intertribal), de forma que as vilas eram um mundo à parte onde eles eram obrigados a retirar, engenhosamente, o que fosse necessário à sobrevivência. E, mesmo que o isolamento aconteça por motivos religiosos, tais grupos buscam a solidão em sítios particulares, como os mais recuados vales, as clareiras abertas no meio da floresta siberiana ou a costa de Massachussets, revelando assim exemplos de uma "geografia social" (o termo é de Vidal). Outra causa reside nos traços físicos de uma região: o conhecimento da fisionomia de um país causa impacto significativo em sua dinâmica migratória. Igualmente, a extrema divisão da propriedade e a necessidade de mão-de-obra tanto numerosa quanto hábil demandada pelo cultivo de arroz nas sociedades do Extremo Oriente, exigindo a participação das mulheres e dos vizinhos, acaba por fortalecer os laços familiares e da vila como um todo.

De outro lado, cabe avaliar que o regime social também reflete na geografia, pois "tudo é ação e reação". Dessa forma, Vidal quer dizer que há, em nome de interesses econômicos de certos grupos sociais, uma má utilização das potencialidades geográficas. É o que aconteceu com as grandes plantações de café. Nos EUA, elas submeteram a riqueza do solo, que poderia nutrir boa parte da população, a um único produto, e os negros "a uma das formas de escravidão mais odiosas e cruéis". No Brasil, critica o alto custo das mercadorias e do crédito impedindo o surgimento de pequenas propriedades, bem como a insalubridade do porto de Santos, escolhido pela proximidade com os centros produtores. Não existiria, nas entrelinhas dessa retórica, uma justificativa para a exploração dos recursos coloniais? A alegação de que somente os europeus, dotados das mais avançadas técnicas, poderiam extrair as potencialidades adormecidas localizadas nos territórios d'outre-mer, beneficiando a todos? Suas palavras podem soar como advertência: 
"A existência de um produto de primeira necessidade, localizado em um espaço específico, pode engendrar consequiências sociais e políticas" (ibidem, p.13, grifo nosso).

Esse é o sentido social da geografia vidaliana: a estratégia. Não no sentido de fazer dela um instrumento de combate, mas sim no esforço de fazê-la uma ciência voltada para o conhecimento das características físicas da superfície terrestre e suas especificidades regionais. Tais características são matrizes com as quais as civilizações se defrontam no decorrer de sua história e que, para conviver com elas ou mesmo superá-las, precisam construir artifícios capazes de permitir sua reprodução. Portanto, a Geografia diz respeito ao estudo das distintas estratégias civilizacionais de desenvolvimento, das táticas que são forjadas na relação com o habitat. Há uma disputa pela vida, cujo desdobramento geográfico é, precisamente, a habilidade de se relacionar com o meio de maneira a otimizá-lo o máximo possível. Dada a evidência de que os lugares não são "auto-sustentáveis", ou seja, não possuem a totalidade das condições físicas e humanas necessárias para a sobrevivência de suas populações, há uma dependência entre eles onde, inevitavelmente, as escalas se articulam. Por sua vez, a extensão de tal articulação dependerá da combinação entre a capacidade técnica e o sítio em que os grupos sociais estão inscritos. Esta combinação, decerto, engloba uma série de fatores, como a transformação da paisagem, a criação de utensílios técnicos e as particularidades culturais (língua, vestimentas, alimentação, costumes). Porém, seu resultado mais inpun tante ¿̇ a formação de um vasto mosaico de gêneros de vida, isto é, diferentes capacidades de adaptação e modificação frente ao ambiente. Portanto, a tarefa do geógrafo será sempre a de adquirir uma visão de conjunto, reunindo, essencialmente, três elementos: o homem, o meio e a técnica.

Assim sendo, não é difícil assimilar porquê Vidal parece muito impressionado com o processo de ocupação territorial dos Estados Unidos da América (VIDAL DE LA BLACHE, 1899:104), país que conheceu em 1905. A grandiosidade do espaço, as longas missões de exploração e a restrição dos acidentes físicos não foram suficientes para conter a energia e a vitalidade dos procedimentos de indústria e engenharia lá aperfeiçoados. Por intermédio da técnica, a hostilidade geográfica inicial foi convertida em impulso para o progresso ulterior. Porém, não se trata apenas de mudanças geográficas. Vidal reconhece também seus impactos sobre as relações sociais: a mentalidade e os hábitos de vida americanos não são os mesmos encontrados na Europa (VIDAL DE LA BLACHE, 1902:20).

Outra geografia, outra sociologia. Em termos conceituais, visava-se mapear as diversas civilizações que habitavam a superfície terrestre, evocando culturas, técnicas, línguas e costumes inscritas em cada uma delas. A preocupação de Vidal não se restringia apenas à forma, mas recaia sobre a maneira de fazer e agir sobre o meio. Um dos traços emergentes de sua perspectiva é uma geografia do cotidiano, uma "micro-geografia" a narrar os costumes do homem comum. Aqui a influência da Sociologia e da Etnografia salta aos olhos, atentando para a comida, bebida, 
vestuário e gestos dos camponeses franceses. Ele chega a falar em "civilização material", termo empregado no La France. Tableau géographique (1903) para designar os gêneros de vida do mundo mediterrâneo: a exploração do solo, o cultivo e a transumância, as árvores frutíferas, o uso do azeite e do vinho combinado com o trigo e o pão (VIDAL DE LA BLACHE, 2007:342 [1903]).

Enfim, a riqueza da Geografia vidaliana contrasta com a interpretação promovida por Lucien Febvre em 1922. Sob o argumento de defendê-la perante os ataques da Sociologia durkheimiana, o co-fundador dos Annales d'histoire économique et sociale localiza seu papel como mera "introdução geográfica à História", bem como vincula-a ao rótulo "possibilista" (FEBVRE, 1991) que, de fato, nunca lhe pertenceu. Como desdobramento dessa leitura, forjou-se não somente uma subordinação da Geografia perante a História, mas também o isolamento dos geógrafos em relação aos sociólogos e um obstáculo rumo ao "desabrochar uma geografia social ou política nova" (DOSSE, 2004; 1992:82). Mais recentemente, sociólogos como Anthony Giddens, Zygmunt Bauman e mesmo Renato Ortiz realizam uma aproximação com a Geografia que, se num primeiro momento pode parecer frutífera, deve ser questionada em seu âmago: ao invés de incorporá-la como referencial importante no entendimento dos fenômenos provocados pela globalização, preferem aderir a um discurso do fim das fronteiras, dos territórios e do espaço como um todo (GIDDENS, 1991 [1990]; BAUMAN, 1999 [1998]; ORTIZ, 2003 [1994]). Afinal, qual o significado político por trás dessas leituras?

Que a Geografia e a Sociologia se reencontrem sub novas bases. $O$ pensamento de Vidal de la Blache pode ser um dos caminhos a trilhar.

\section{Guilherme Ribeiro}

\section{Referências Bibliográficas}

BAUMAN, Zygmunt. 1999 (1998). Globalização: as consequências humanas. Rio de Janeiro: Jorge Zahar.

DOSSE, François. 1992 (1987). A História em Migalhas: Dos "Annales" à Nova História. Campinas: Editora da Unicamp/Ensaio.

- 2004. O recurso geográfico dos historiadores. In: DOSSE, François. História e Ciências Sociais. Bauru: Edusc.

DURKHEIM, Émile. 2001 (1895). As Regras do Método Sociológico. São Paulo: Martin Claret.

FEBVRE, Lucien. 1991 (1922). A Terra e a Evolução Humana. Introdução Geográfica à História. $2^{\text {a }}$ ed. Lisboa: Cosmos.

GIDDENS, Anthony. 1991 (1990). As Consequências da Modernidade. São Paulo: Unesp. 
LANGLOIS, Charles-Victor, SEIGNOBOS, Charles. 1992 (1898) Introduction aux Études Historiques. Paris: Kimé.

ORTIZ, Renato. 2003 (1994). Mundialização e Cultura. São Paulo: Brasiliense. RHEIN, Catherine. 1982. La Géographie, discipline scolaire et/ou science sociale? (1860-1920). Revue française de Sociologie. Paris, XXIII.

VIDAL DE LA BLACHE, Paul. 1899. Leçon d'ouverture du cours de Géographie. Annales de Géographie, VIII année, $\mathrm{n}^{\circ} 38$.

- - 1902. Les conditions géographiques des faits sociaux. Annales de Géographie, année XI, $\mathrm{n}^{\circ}$ 55, pp.13-23.

1903. La géographie humaine. Ses rapports avec la géographie de la vie. Revue de synthèse historique, vol. 7 agosto-dezembro.

—. 2007 (1903) La France. Tableau géographique. In: RIOUX, Jean-Pierre. Tableaux de la France. Michelet, Duruy, Vidal de la Blache et Bruno.

- 1904. Rapports de la Sociologie avec la Géographie. Revue Internacional de Sociologie, XII année, n.5, maio.

- 1913. Les caractères distintifs de la géographie. Annales de Géographie, XXII année, $\mathrm{n}^{\circ} 112$. (versão em português: As características próprias da geografia. In : Christofoletti, A. (org.) Perspectivas da Geografia. São Paulo : Difel, 1982) 